\title{
ANÁLISIS DE LA IGLESIA PARROQUIAL DE SANTA MARÍA DE CASTRO (CERVANTES, LUGO)
}

\author{
REBECA BLANCO ROTEA \\ Laboratorio de Arqueoloxía do Instituto de Estudios Gallegos «Padre Sarmiento» \\ (CSIC-Xunta de Galicia)
}

\begin{abstract}
Resumen
La Iglesia de Santa María de Cervantes es una pequeña iglesia parroquial situada en una zona de montaña al Oeste de la Sierra de Los Ancares. Se emplaza sobre un castro del período de transición del mundo prerromano al romano y sobre una necrópolis de época bajomedieval. Esta iglesia se ha estudiado desde la Arqueología de la Arquitectura, aplicándose la lectura de paramentos como metodología para su análisis desde una perspectiva arqueológica, que se cree ha aportado importantes avances a su conocimiento y al de las iglesias rurales de la zona de los Ancares lucenses (Lugo, Galicia).

\section{Palabras Clave}

Arquitectura Eclesiástica; Arqueología de la Arquitectura; Arquitectura Rural; Análisis Estratigráfico.
\end{abstract}

\begin{abstract}
Santa María de Cervantes Church is a little building that it is situated in a mountain area in the west of the Ancares Sierra. It is sited over a hiltfort and a high mediaeval necropolis. This church was studied from the Archaeology of Architecture, it was applied the methodology of stratigraphic analysis of elevations, for its analysis from an archaeological perspective. This investigation it thinks that it has contributed important advances to this church and to another rural churches sited in the Ancares of Lugo (Galicia).
\end{abstract}

\section{Key Words}

Eclesiastic Architecture; Archaeology of Architecture; Rural Architecture; Stratigraphic Analisys. 


\section{INTRODUCCIÓN ${ }^{1}$}

La iglesia de Santa María de Castro se localiza en el municipio de Cervantes (Lugo), en un pequeño valle de montaña situado en el W de la Sierra de los Ancares. Se asienta sobre un yacimiento castreño y una necrópolis cristiana, localizados en un pequeño saliente de ladera originado por el río Quindós, afluente del Navia. Es precisamente su situación en la cuenca alta del río Navia, rica en recursos auríferos, según recientes estudios realizados por el equipo a cargo de las excavaciones del castro, la que explica la ocupación de este territorio desde época romana y la misma existencia del castro.

En el año 1994 durante las obras de remodelación del acceso a la iglesia de Santa María, quedan al descubierto una serie de estructuras que motivaron la realización de tres campañas de excavación en los años 1995, 1996 y 1999, a instancias de la Dirección Xeral de Patrimonio Cultural (en adelante DXPC) y ejecutadas por la empresa arqueológica Terra Arqueos. Estas intervenciones, que contemplaron excavación, consolidación y acondicionamiento de los restos, documentaron la existencia de un castro posteriormente ocupado por una necrópolis cristiana de época posiblemente bajomedieval.

A la hora de abordar el estudio de la iglesia de Santa María de Castro, y con la intención de establecer un acercamiento a aspectos referidos a su localización geográfica y su etapa de formación, eran básicos los datos facilitados por la excavación del castro y la necrópolis (González, L.F., Álvarez, Y. y López, M.A. 1996, 1999; González, L.F., Álvarez, Y. 2000). En este sentido, la primera aproximación que se realizó al análisis de la iglesia de Santa María de Castro se hizo a través de la comprensión de las ocupaciones existentes con anterioridad a la iglesia, el castro y la necrópolis, ya que podían proporcionar datos de gran interés a su estudio.

La iglesia parroquial había sido catalogada recientemente como contemporánea (s. XX) (Fernández 1998), sin embargo erain varios los datos que apuntaban a

\footnotetext{
${ }^{1}$ A este trabajo han contribuido Pilar Prieto Martínez (en la elaboración de dibujos de campo iniciales), César Parcero Oubiña, Eloi Saavedra Vidal (ambos en la toma de datos en campo con estación total) [todos ellos son o han sido miembros de Laboratorio de Arqueología, IEGPS (CSICXuGa)], Alicia Padín Otero (sistematización de datos) [antiguo miembro del Laboratorio de Arqueología y Formas Culturales del Instituto de Investigaciones Tecnológicas de la USC], y, especialmente, Cristina Brión Calo, como colaboradora de este último Laboratorio, quien estuvo presente en los procesos de trabajo de campo y de gabinete del análisis de la iglesia de Santa María de Castro, encargándose del vaciado documental y las fases de lectura del edificio en campo. Finalmente, agradecer también a Anxo Rodríguez Paz (miembro del Laboratorio de Arqueoloxía del IEGPS) su contribución y asesoramiento en la elaboración de la parte gráfica.
} 
que podría enclavarse en una cronología anterior; concretamente la existencia de unas pinturas murales (descubiertas durante las intervenciones arqueológicas anteriormente citadas) en una pequeña ventana situada en el testero, en la actualidad cegada tapando en parte las pinturas, así como la propia forma de la ventana, alancetada, que hacían pensar que esa cronología podría ser errónea.

Estos datos llevaron a plantear la necesidad de realizar un estudio exhaustivo desde una metodología distinta, ya que la ausencia de elementos estilísticos o tipológicos o el tipo de técnica constructiva empleada imposibilitaban fechar correctamente el edifício desde planteamientos más clasicistas propios de otras disciplinas. En el mes de octubre del 2001 comenzaron los análisis que concluyeron en abril del 2002 y se llevaron a cabo con un equipo permanente de dos personas.

\section{EL CASTRO DE CERVANTES (SANTA MARÍA DE CASTRO, LUGO) ${ }^{2}$}

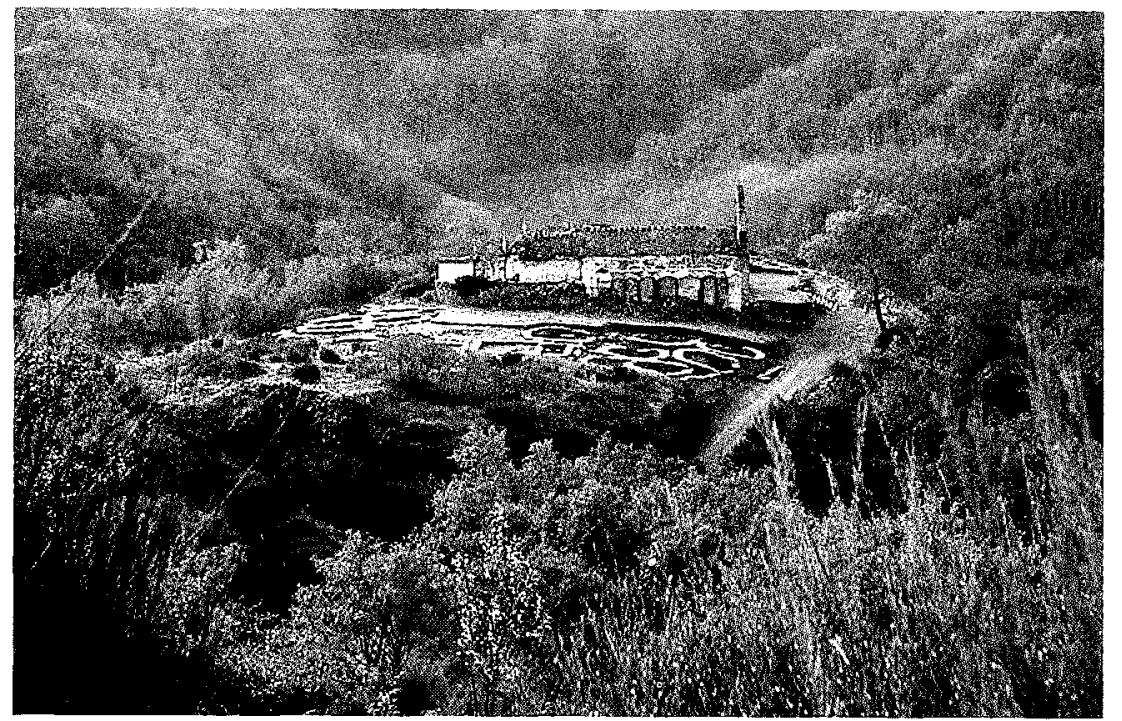

Figura 1. Emplazamiento del Castro e Iglesia de Santa María de Castro (Cervantes, Lugo).

\footnotetext{
${ }^{2}$ Para la elaboración del apartado referido al Castro de Santa María de Cervantes, que serviría para contextualizar el emplazamiento, problemática y análisis de la iglesia parroquial ubicada sobre este castro, se han empleado los trabajos realizados por López González, L.F., Álvarez González, Y. y López Marcos, M.A. (Empresa Arqueológica TERRA ARQUEOS S.L.) que se recogen en la bibliografía. Sus aportaciones han sido de gran ayuda para la elaboración del análisis de la iglesia y del presente trabajo.
} 


\section{Emplazamiento}

El poblado castreño de Santa María de Castro está ubicado en la región Noroeste de la Península Ibérica, en la zona oriental gallega, en la cabecera del río Navia. Se enmarca en una zona de montaña al Oeste de la Sierra de los Ancares. Desde esta sierra las alturas van descendiendo hacia el río Navia en el que desemboca el río Quindós en cuya márgen izquierda se sitúa el asentamiento. La región se caracteriza por ser una zona de enlace entre la comunidad gallega y el principado asturiano a través del cauce del río Navia.

Concretamente se sitúa en un valle estrecho entre montañas que impiden obtener una buena visibilidad de su entorno. Su emplazamiento, en un espolón, queda determinado por la propia estrategia económica del poblado, al situarse al lado de varias explotaciones auríferas, lo que a la vez determina parte de su morfología actual, puesto que parte de los elementos de delimitación del castro, en concreto los fosos, fueron ejecutados aprovechando la fuerza hidráulica proporcionada por los canales de agua que se dirigen a las minas de oro mencionadas.

\section{Contexto histórico}

El contexto histórico transcurre durante el período de transición del mundo prerromano al romano, en una región caracterizada por su gran riqueza en recursos de todo tipo. Sin embargo, dentro de este marco histórico va a tener especial relevancia la existencia de abundantes recursos auríferos, lo que condicionará la gran transformación que va a sufrir toda la región ya que será la principal actividad económica de esta zona durante época romana.

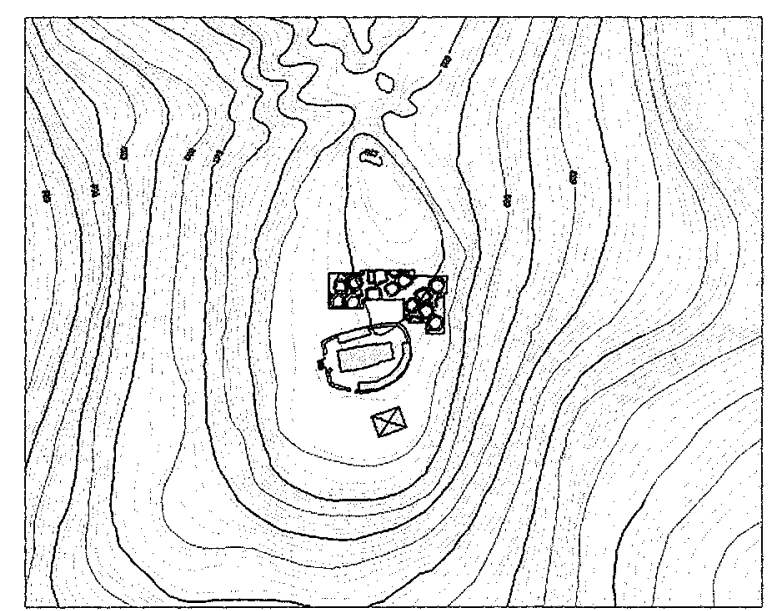

Figura 2. Planimetría con el emplazamiento del Castro y la Iglesia de Santa María de Castro (Cervantes, Lugo), proporcionado por la empresa arqueológica Terra Arqueos S.L. 


\section{Organización interna del poblado}

El asentamiento cuenta con un recinto principal y dos aterrazamientos por su sector Sur. El recinto superior presenta una planta de forma ovalada, está bien delimitado en su perímetro por una muralla de aterrazamiento, realizada en su parte Norte a modo de parapeto, separada de la ladera por tres líneas de fosos.

La superficie con mejores condiciones de habitabilidad se sitúa en el recinto central, en donde se realizó una intervención durante las campañas de 1995-96 y 99, dejando al descubierto una serie de estructuras que se corresponden con el poblado de época romana.

El aspecto más destacado de los restos es el buen estado de conservación de los mismos, sobresaliendo la altura de los paramentos de las cabañas que en algunos de los casos supera los dos metros y medio.

\section{Conclusiones generales}

El castro es un poblado de nueva planta, con una ocupación claramente contemporánea a la explotación de las minas. Presenta un único nivel de ocupación, fechado entre el año 50 a.C y el siglo II d.C. Las unidades familiares son independientes y morfológicamente similares a las de los poblados castreños prerromanos. El emplazamiento del poblado no ha tenido en cuenta factores que eran importantes en época romana (como por ejemplo: amplia visibilidad, constituir un referente espacial en el entorno, proximidad a vías de tránsito o a recursos agropecuarios). Destaca también la ausencia de espacios anexos a las cabañas. La actividad económica fundamental que se realizaba en el poblado era la explotación minera. El abandono se produce de forma generalizada en el siglo II d.C, pero aunque se abandonan la mayoría de las cabañas, continúa un poblamiento de modo residual del que se desconoce su fecha por el momento.

\section{LA NECRÓPOLIS CRISTIANA}

\section{Descripción de la necrópolis}

Sobre el castro anteriormente descrito, se localizó una necrópolis cristiana, posiblemente bajomedieval, que ofrece un especial interés para el estudio de la iglesia. La necrópolis se extiende por todo el sector W excavado en el yacimiento; en la totalidad de las campañas se han documentado 63 enterramientos. Tipológicamente se trata de sepulturas antropomorfas realizadas en mampostería de piedra esquistosa, sin preparación de suelo. Las paredes están formadas por mampostería colocada en hiladas horizontales o de canto (muchas veces se reutilizan parte de

Cuadernos de Estudios Gallegos, Tomo LII, Fascículo 118, Santiago 2005. (Págs. 9 - 38) 
los muros de las construcciones del castro como paredes de las sepulturas o se reutilizan los materiales del poblado castreño) y están tapadas con grandes lajas selladas con argamasa. Algunos de los cuerpos se encontraban inhumados con sudario. La aparición de una moneda fechada en los siglos XIII-XIV en una fosa asociada a la necrópolis, remonta su existencia a época bajomedieval.

\section{Relación de la necrópolis y la iglesia de Santa María}

Según los autores anteriormente citados (López González et ali 1996: 22) la necrópolis correspondería posiblemente a los primeros momentos de funcionamiento de la capilla de Santa María y reflejaría un uso continuado en el tiempo que se remontaría al menos a época bajomedieval. El estudio de la iglesia partía de esta misma hipótesis, siendo probable que la edificación actual de la iglesia se asiente sobre los restos de una primera edificación que correspondería a esta época, aunque no se podía corroborar este dato hasta que se efectuase un análisis exhaustivo del edificio. De esta primera fábrica y fundación con categoría de capilla o parroquia no se cuenta con ninguna referencia documental. Hasta el s. XVI no aparecen menciones de la capilla de Santa María de Castro y se cree que la fábrica actual no se remonta más allá de principios del s. XVI o finales del XV, como se verá más adelante.

Por ello la necrópolis reviste una importancia primordial: es el elemento que otorga una fecha de inicio, sino para los restos conservados, sí para la fundación de la iglesia. Ésta, por otra parte, se explicaría en la tradición cristiana de cristianización de lugares paganos efectuada por la Iglesia desde época altomedieval.

\section{LA IGLESIA PARROQUIAL DE SANTA MARÍA DE CASTRO}

Santa María de Castro es una pequeña iglesia rural de planta basilical absidiada. Se compone de nave única de planta rectangular y ábside de menor altura que la nave, también de planta rectangular. Debe indicarse (véase figura 5) que tanto la nave como el ábside no guardan proporciones regulares, se cree que fruto de las modificaciones que ha ido sufriendo la iglesia a lo largo del tiempo. La iglesia cuenta en la actualidad con dos vanos de entrada, situados en sus fachadas S y W, ambos rematados al exterior por arcos de medio punto dovelados, con derrame al interior, el $\mathrm{S}$ adintelado y el $\mathrm{W}$ rematado en arco escarzano. Asimismo, se conservan cinco ventanas en su fachada meridional, todas ellas irregulares, con doble derrame y rectangulares al exterior e interior, exceptuando la más occidental abierta en el ábside que es de medio punto al interior. En el testero se conserva también una pequeña ventana alancetada, cegada en la actualidad.

Cuadernos de Estudios Gallegos, Tomo LII, Fascículo 118, Santiago 2005. (Págs. 9 - 38) 


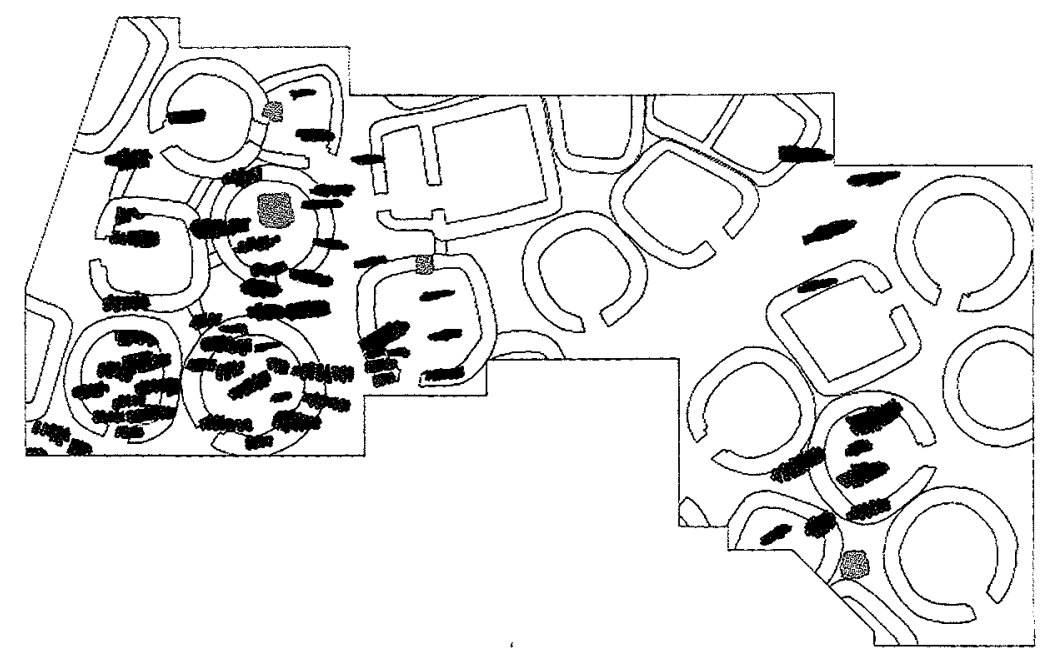

Figura 3. Planta de las tumbas exhumadas durante las excavaciones arqueológicas, proporcionada por la empresa arqueológica Terra Arqueos S.L.
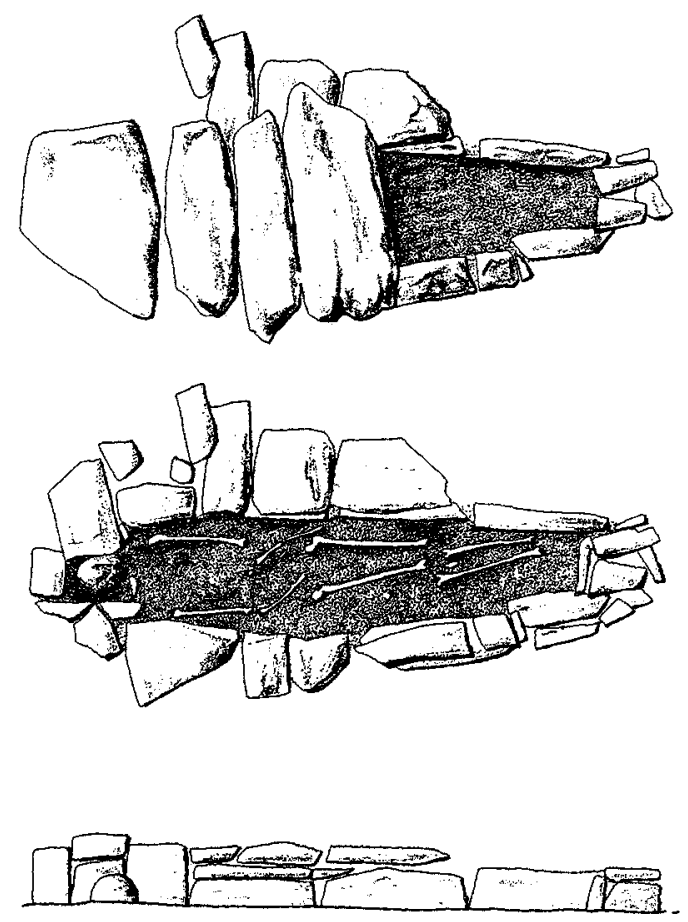

Figura 4. Dibujo de una de las tumbas exhumadas, imagen proporcionada por la empresa arqueológica Terra Arqueos S.L. 


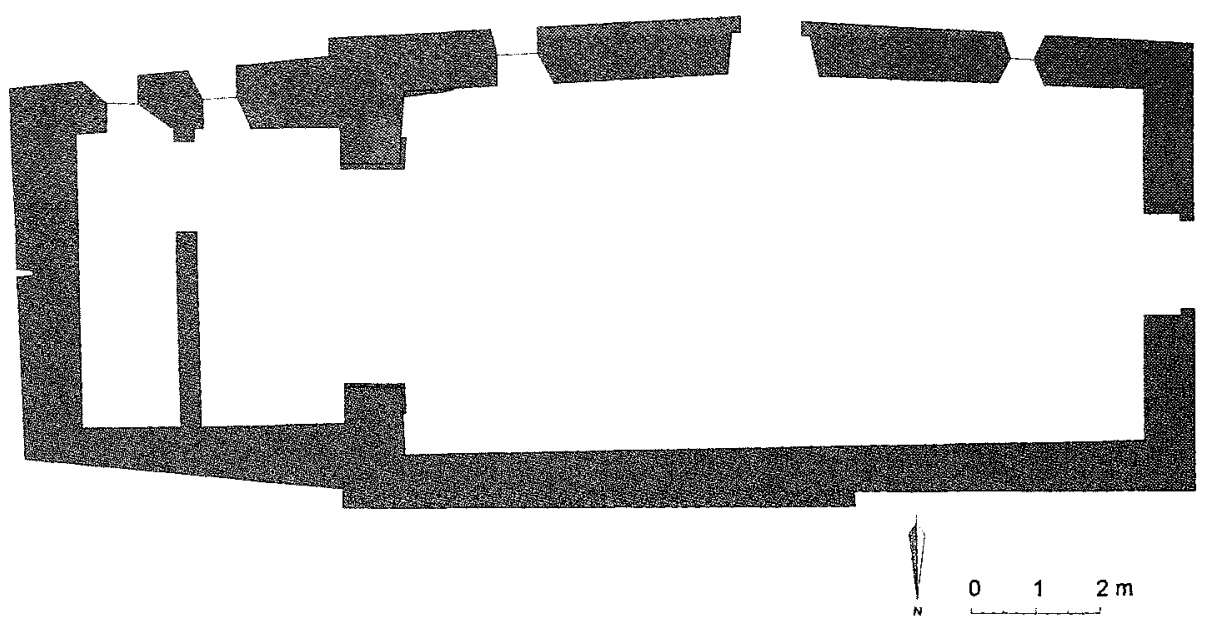

Figura 5. Planta de la iglesia de Santa María de Castro.

Toda la fábrica está realizada en aparejo de mampostería de lajas de esquisto, posiblemente revestida en su totalidad al exterior, conservándose el revestimiento en algunas zonas, como se verá más adelante. Se debe indicar que el edificio carece de elementos de estilo, con excepción de la ventana alancetada anteriormente citada y una espadaña de tres cuerpos que corona su fachada W.

\subsection{Vaciado documental y análisis histórico ${ }^{3}$}

En relación con el estudio arquitectónico de la iglesia parroquial de Santa María de Castro, se ha considerado necesario realizar también un análisis de las fuentes documentales conservadas y el consiguiente estudio histórico de la misma, con el fin de obtener una serie de datos históricos que clarificasen y ayudasen a verificar las conclusiones obtenidas mediante el estudio estratigráfico de dicho edificio.

Se comenzó esta parte del trabajo con la consulta de material bibliográfico que hiciese referencia a la iglesia de Santa María atendiendo a dos aspectos:

- las posibles referencias a su existencia como entidad histórica, es decir, referencias a la parroquia dentro del arciprestazgo de Cervantes,

- y las referencias alusivas a la edificación propiamente dicha, recurriendo a fuentes ya clásicas para el estudio de monumentos artísticos dentro del ámbito gallego.

\footnotetext{
${ }^{3}$ Los datos referidos a este apartado fueron recopilados por Cristina Brión Calo.
} 
Antes de pasar a analizar los datos obtenidos en esta fase del trabajo, debe indicarse que la búsqueda no proporcionó abundantes datos, ya que la falta de referencias a esta iglesia es general y posiblemente venga justificada por la escasa entidad de la parroquia a lo largo de las Edades Moderna y Contemporánea en el arciprestazgo de Cervantes.

\section{Referencias a su existencia como parroquia y edificación}

\section{Fuentes consultadas no publicadas}

Archivo Diocesano de Lugo

La documentación original perteneciente a la parroquia se encuentra en su mayor parte en el Archivo Diocesano de Lugo. Las referencias más antiguas se remontan a los siglos XVI y XVII. Los datos de interés recogidos en las fuentes consultadas son escasos. El primero de ellos nos habla de que en el año 1686 ya existe la parroquia como tal. Sin embargo, el dato más antiguo localizado se encuentra en el Libro de Beneficiales, Mazo 2, donde se localiza la presentación del beneficio de esta iglesia en el año 1584. Ésta es, hasta ahora, la referencia de mayor antigüedad encontrada para Santa María como parroquia y como edifício. El primer legajo del Mazo 2, presenta bajo el epígrafe Beneficial de Santa María de CastroMayor, un abultado documento que trata sobre la «presentación de la iglesia y beneficio de Santa María de CastroMayor», resaltando su condición de «vacante» (folio 2). Se encuentran aquí las referencias más antiguas tanto a la existencia de la parroquia como entidad jurídica, como a la existencia de la edificación eclesiástica, que en estos años del s. XVI se denomina capilla. Tras este beneficio de 1584, se han localizado otros beneficios que llegan hasta 1904.

También se localizó un volumen de principios del S. XVIII bajo el siguiente epígrafe Libro de todos los Curatos que hay en el Obispado. Año de 1700. Se trata de un libro de visitas, donde se recogen las visitas realizadas a todas las parroquias de la Diócesis entre 1700 y 1703 por el Obispo D. Lucas Bustos. Sobre la iglesia de Santa María, recoge lo siguiente (Fol. 207 y 207\%): «Santa María de Castro, cura Manuel Diaz de Guitian de hedad de 50 años: es de libre colocación, lleva el cura todos los putos, primicias la yglesia. Vale el Curato Trescientos Ducados: ai sacramentos, pila bautismal, chrismeras de plata, esta pobre de ornamentación: Maymo Franco Rodriguez tiene de alcance final la iglesia a su favor 251 Rs queda com'n al cura para su cobrança, y le queda mandado ponga un pie de plata al caliz, que le tiene de estaño, y con el residuo y lo que adelante caieve, que compre un ornamento de Damasco encarnado y blanco: no hay cofradia, ni capellania, ai una hermita de San Miguel que esta reparada: no ai sacerdote». 


\section{Fuentes bibliográficas publicadas}

Las referencias de mayor antigüedad ya editadas proceden del Episcológico Lucense de 1755 recogido por López Valcárcel (1991) en su apéndice III, donde se recoge un documento que coincide con el Libro de todos los curatos de la Diócesis, confeccionado con motivo de la visita pastoral de 1700-1703.

Ya en el s. XX existen datos sobre la parroquia, la renta y su dotación; en la Guía Eclesiástica de la Diócesis de Lugo (VV.AA. 1915: 53) se recoge la siguiente referencia: «CASTRO, Santa María, -E- Anc. De Cervantes. Tiene $360 \mathrm{~h}$ de casa rectoral, 1.100 de dotación y 140 de fábrica. Existe la capilla de San Miguel, propiedad de la iglesia. Párroco D. Angel Prado».

En la Guía de la Diócesis de Lugo (López Valcárcel 1996) se hace referencia a los siguientes datos de interés: la parroquia presenta 111 habitantes; la superficie del territorio parroquial es de 1195,6 h; los barrios y lugares que integran el conjunto parroquial son: Bona, Buslelo, Couso, Río, Sabadelle y Vilaluz; capillas existentes en la feligresía propiedad de la iglesia: S. Miguel de Vilaluz; datos históricos: su condición, en este caso Única, y Anejo, situación que modificó en 1686.

Acerca de la antigüedad que pueda tener la parroquia de Santa María de Castro, cabe destacar un documento que podría hacer referencia a ella, pero que no se ha conseguido contrastar por el momento. El documento se titula Toponimia Gallega y se recoge en el T. VIII del Boletín de la Comisión Provincial de Monumentos Históricos y Artístico de Lugo (VV.AA. 1969-70): «Castro, en Santa Cruz y San Román de la Retorta (1089)» / "Castro antiguo quodis inter Sancta Cruce et Sancto Romano» / "Donación de la Condesa Elvira a la Iglesia de Lugo (=1123, 1130, 1167)». Si realmente hace referencia a este edificio, probablemente se trate de donaciones anteriores a la creación de la parroquia, dato que como decimos no hemos podido contrastar.

\section{Referencias en estudios histórico-artísticos}

Son muy escasos los datos referentes a cuestiones tipológicas, estilísticas o simplemente artísticas localizadas en la bibliografía consultada. No existe ninguna referencia de este tipo en la bibliografía consultada no publicada. En cuanto a la bibliografía publicada existen dos obras que abordan, de manera desigual, el estudio de la iglesia.

La primera en el tiempo se recoge en el T. II del Inventario artístico de Lugo y su provincia, T. II (Valiña Sampedro 1975). En ella, tras exponer algunos datos sobre su localización geográfica, se analizan algunos aspectos formales del edificio: «[...] Espadaña de dos vanos, nave, arco de acceso de medio punto sin imposta; presbiterio más bajo y reducido; arco triunfal de medio punto, sobre pilastras. 
Reparaciones no muy acertadas, con ladrillo. Santa María, moderna, con gran peana de nimbo con ángeles» (id.: 98). Ofrece además una planta de la iglesia.

La obra que aborda de forma más exhaustiva su estudio es la tesis doctoral de Fernández Gómez (1998) El arte religioso en la Sierra Oriental de la provincia de Lugo, por las tierras del camino primitivo. ss. XVI-XX. Catalogación.

En ella, la autora realiza una catalogación de los elementos de interés históricoartístico de esta parroquial: arquitectura, escultura y orfebrería. En cuanto a los primeros, aborda un estudio formal de los mismos. La entrada de Santa María de Castro recoge la siguiente referencia:

«Planta: De salón, de una sola nave (14.16 x 5.30). / Alzado interior: Nave cubierta de madera, adintelada. / Presbiterio reducido, al cual se accede bajo amplio arco toral. / Muros enlucidos. / Alzado exterior: Espadaña de tres vanos sobre el frontis, nave con cubierta a dos aguas y cabecera semicircular, cubierta a una sola agua. / Autor: Desconocido. / Cronología: s. XX. / Estilo: Historicismo clasicista».

\section{Algunas notas sobre la pintura}

Durante la excavación del castro, el equipo detectó la existencia de unas pinturas situadas en el abocinamiento de la ventana del testero. Éstas están en bastante mal estado de conservación y destruidas en parte por el tapiado de dicha ventana por el interior del ábside. En la parte superior izquierda, se puede observar un sol dibujado en tonos rojizos sobre un fondo azulado, sobre el que también se disponen estrellas de ocho puntas. En la parte superior derecha también se observa el mismo fondo azulado con dos estrellas de las mismas características y una luna en tonos blanquecinos. Sin embargo, debemos indicar que las estrellas están desdibujadas, sólo se conserva su negativo, y el fondo azulado tampoco se aprecia apenas. Este estado, unido a su difícil visibilidad, explica que hayan pasado totalmente desapercibidas hasta el momento, por lo que no existe ningún estudio de pintura mural que las mencione.

La lectura estratigráfica realizada en el edificio, nos lleva a situar las pinturas murales en una fecha posterior a finales del s. XV, momento en que se dató la fase tardogótica. Si a ello unimos los datos extraídos de la consulta bibliográfica realizada, nos lleva a situar dichas pinturas en torno al s. XVI, pues es en este siglo donde hemos encontrado mayores similitudes iconográficas con las pinturas conservadas en Santa María de Castro.

Según García Iglesias (1979), es habitual que el tratamiento pictórico del interior de los templos ocupe la totalidad del espacio. En el siglo XVI suele estructurarse en bandas, y se adapta al formato arquitectónico y al programa pictórico en el 


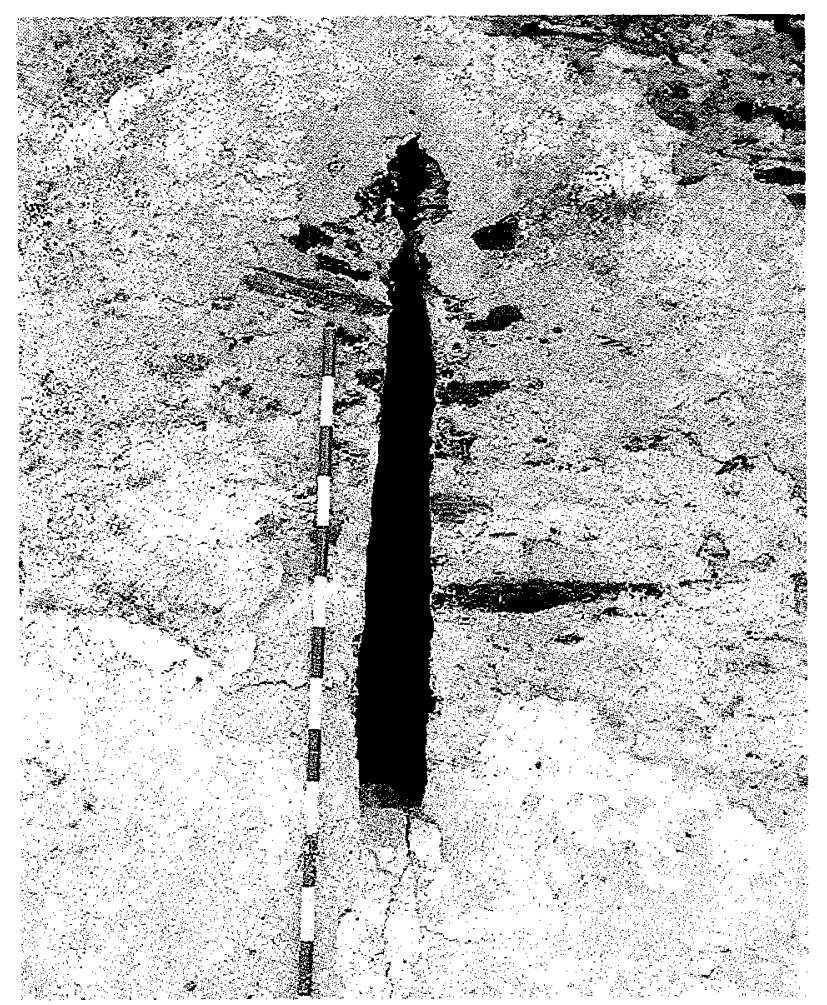

Figura 6. Ventana del testero en cuyo abocinamiento se localizan las pinturas.

que se integra, lo cual es especialmente importante en la época manierista. En cuanto a la temática, el mismo autor opina que la representación de un cielo estrellado en las cubiertas o paredes, remarcaría la idea de apertura espacial.

El hecho de que las pinturas ocupen en esta iglesia un espacio tan marginal, además de relacionarse con la búsqueda espacial que está tan ligada al arte de este momento, se cree que podría estar en relación con la temática posiblemente desarrollada en el resto del muro interior del presbiterio (actualmente encalado). Con ello se considera que probablemente este espacio estaría pintado en este periodo y que las pinturas de la ventana formarían parte de un programa iconográfico más amplio, hecho que no se podrá comprobar hasta que se efectúe la restauración de la misma y se levanten los encalados. Así, el mismo García Iglesias (1979) opina que «cuando el templo está dedicado a la Virgen se ocupa con episodios relativos a su vida, generalmente ligados al nacimiento e infancia de Jesús, la parte correspondiente a la Capilla Mayor». Éste podría ser, de conservarse, uno de los temas iconográficos representados en esta parroquial. 
En cuanto a la iconografía, se conservan paralelismos en otras obras del S. XVI, sobre todo en su segunda mitad: como las del Presbiterio de la Iglesia de San Bartolomé de Rebordáns, las de San Pedro de Ribas Altas, las de San Estebo de Pousada o las de San Lorenzo de Fión. En todas ellas se sitúa esta escena en relación con el tema del Juicio Final.

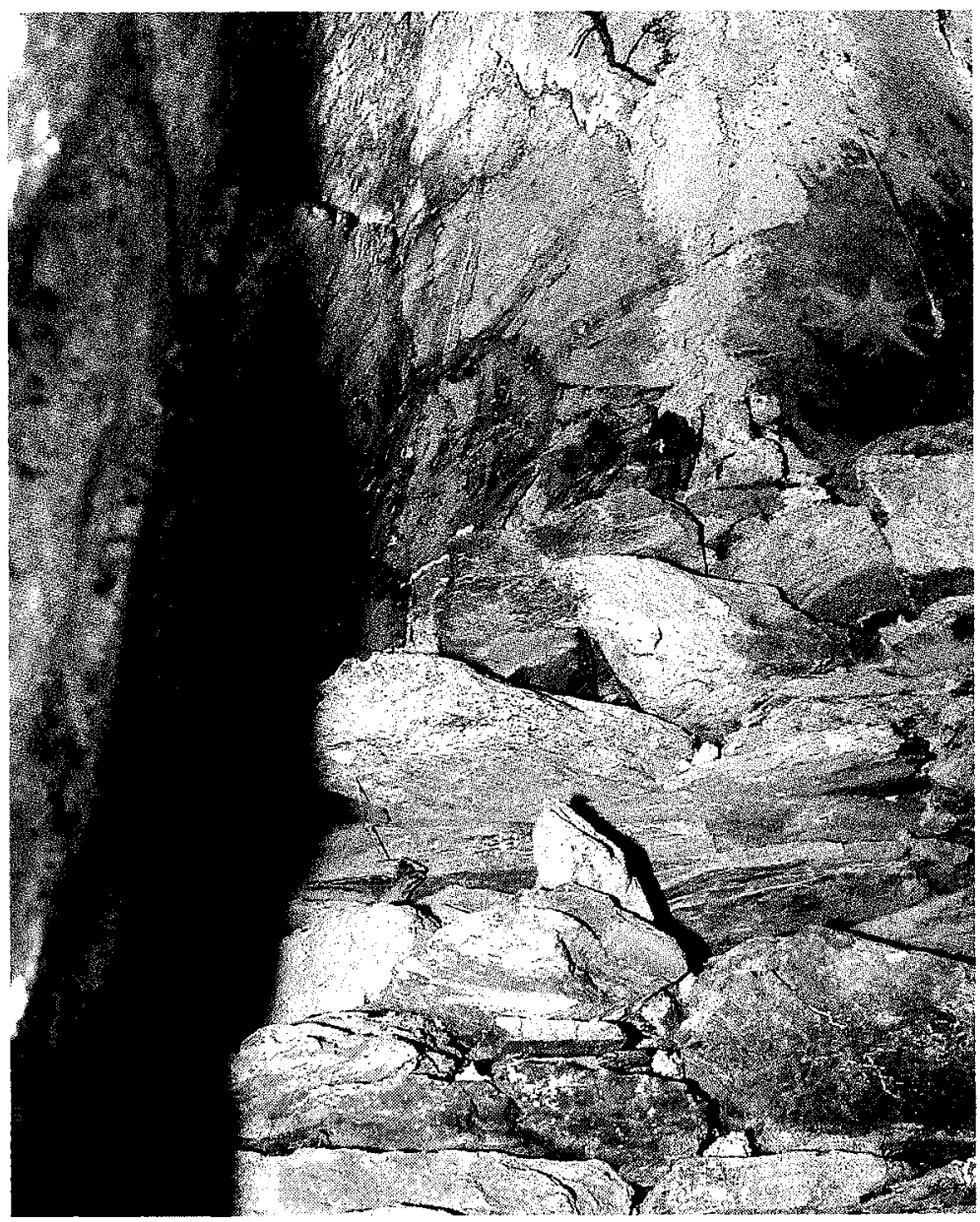

Figura 7. Detalle de las pinturas situadas en la ventana del testero.

Existen otros dos ejemplos que se relacionan con las pinturas de Santa María estilísticamente, situados en el primer tercio del s. XVI: S. Francisco de Pontevedra y Santa Baia de Losón (Lalín). 
(a) El estado de conservación de las pinturas ${ }^{4}$

Ante la posibilidad de que se lleve a cabo una intervención restauradora en el edificio, sería necesario tener en cuenta una serie de cuestiones relativas al estado de conservación de las pinturas murales localizadas en la ventana del testero. También será preciso hacer una previsión de la zona que originalmente podría ocupar el programa iconográfico completo al que pertenecerían estas pinturas, ya que es probable que se extendieran por las paredes del ábside. Para llegar a definir la superficie ocupada por las pinturas será necesario hacer una serie de catas de limpieza sobre estas paredes.

Actualmente esta parte del edificio está parcialmente cegada por un relleno de mampuestos que oculta casi por completo las pinturas. Éstas se encuentran muy afectadas por procesos de deterioro provocados principalmente por la acción de la humedad. Las infiltraciones de agua procedentes de la cubierta a través de grietas y la humedad que llega por capilaridad desde el suelo, ha provocado graves desprendimientos. Las pérdidas de adherencia y cohesión afectan tanto al mortero como a la capa de preparación y la superficie pintada. Esta falta de cohesión en su grado más extremo provoca asimismo la pulverulencia de los pigmentos. Por otro lado, la humedad funciona también como catalizador de los procesos de deterioro provocado por las sales solubles e insolubles que dan lugar a la carbonatación de las capas de preparación y a la formación de costras sobre la superficie de la pintura.

Por último y como resultado de los problemas de humedades, debemos tener en cuenta también el biodeterioro. Las colonias de hongos y algas han provocado concreciones superficiales que ocultan la superficie original.

Para la recuperación de estas pinturas sería necesario desmontar manualmente el muro con el que se ha tapiado la ventana, evitando dañar la superficie pintada en las zonas de contacto. Una vez descubierta toda la superficie ocupada originalmente por las pinturas la prioridad será eliminar aquellas causas que han provocado su deterioro. Para eliminar la entrada incontrolada de humedad será necesario aislar los cimientos del edificio, reparar la cubierta y los desagües y rellenar las grietas existentes. A continuación será preciso corregir las irregularidades del soporte de las pinturas mediante la inyección de morteros de sustitución que, combinado con presión, devolverá la homogeneidad a la superficie de las pinturas. Por último, se abordará la consolidación química de los pigmentos en caso de que exista pulverulencia y se eliminarán las costras provocadas por la acción biológica y la suciedad.

${ }^{4}$ Queremos agradecer a Yolanda Porto Tenreiro (miembro del Laboratorio de Arqueoloxía del IEGPS) sus aportaciones a este trabajo referentes al estado de conservación de las pinturas murales.

Cuadernos de Estudios Gallegos, Tomo LII, Fasciculo 118, Santiago 2005. (Págs. 9 - 38) 


\subsection{Metodología de análisis}

En el análisis de la Iglesia de Santa María de Castro, se ha empleado una de las herramientas metodológicas provenientes de la Arqueología de la Arquitectura: el análisis estratigráfico de alzados (Caballero Zoreda 1995). A continuación describiremos brevemente el proceso de trabajo llevado a cabo:

- Documentación gráfica del edificio. El primer paso del proceso fue obtener una base planimétrica sobre la que trabajar. Se documentó todo el edificio mediante fotografías digitales que posteriormente se rectificaron y ampliaron y sobre ellas, en campo, se diferenciaron las unidades estratigráficas. Se topografió todo el edificio mediante una estación láser, tanto sus volúmenes generales como las unidades estratigráficas diferenciadas en una primera fase, esto permitió, mediante la conversión de los datos a través de un programa informático, obtener la planta y alzados del edificio sobre los que poder trabajar posteriormente.

- Diferenciación de unidades estratigráficas. Se dividió el edificio en sectores de trabajo que coincidían con los alzados del edificio (sector 1: alzado $\mathrm{S}$, sector 2: alzado $\mathrm{E}$, sector 3 : alzado $\mathrm{N}$ y sector 4 : alzado $\mathrm{W}$ ) y se comenzaron a diferenciar mediante la observación visual unidades estratigráficas sobre las fotografias ampliadas y rectificadas. Una vez diferenciadas las unidades en cada alzado, se procedió a otorgarles un número de identificación que figuraría posteriormente en las fichas analíticas (así en el sector 1 se comenzaron a numerar las unidades a partir del número 1000 , en el sector 2 del 2000 , etc.; de esta forma podíamos identificar cada unidad con su sector).

- Registro de la información. Una vez diferenciadas y numeradas todas las unidades se procedió a elaborar las fichas analíticas en campo; se hizo una ficha por cada unidad diferenciada.

- Primera fase de gabinete. En esta primera fase el trabajo se dividió en tres etapas que se llevaron a cabo de forma consecutiva, en primer lugar se informatizaron las fichas analíticas, en segundo lugar se elaboraron los diagramas de sectores y finalmente se simplificaron las unidades (elementos e interfaces) en actividades, es decir, se correlacionaron aquellas unidades que tenían relaciones funcionales y cronológicas entre sí.

- Elaboración de las fichas de actividades. Una vez finalizada la fase anterior se volvió al edificio y se cubrieron las fichas de actividades y se corrigió la documentación gráfica.

- Segunda fase de gabinete. En esta segunda fase se procedió a la informatización de las fichas de actividades, a la elaboración de los diagramas de 
actividades y a la periodización del edificio con la ayuda de los datos obtenidos en el vaciado documental.

- Toma de muestras ${ }^{5}$. Con la finalidad de completar el trabajo realizado en todas las fases anteriores, se decidió llevar a cabo una selección de muestras de morteros y revestimientos en todo el edificio. Este trabajo se ejecutó una vez finalizada la totalidad del análisis del edificio.

\subsection{Síntesis de los resultados obtenidos del análisis de Santa María de Castro}

\subsubsection{Resultados del análisis documental e histórico}

Como se veía más arriba, se han revisado fuentes documentales directas e indirectas, de las cuales se pueden extraer algunos datos interesantes:

- Su catalogación es confusa, ya que unos autores la adscriben a época moderna y otros a época contemporánea (s. XX) de estilo Historicismo clasicista.

- La referencia documental más antigua es del año 1584, momento en que se denomina al edificio como capilla.

- Las fuentes escritas posteriores a este año no ofrecen datos de interés, tan sólo una referencia cronológica a su existencia. Algunos de ellos, ya en el S. $\mathrm{XX}$, nos hablan de reparaciones puntuales.

- La escasez de referencias al edificio dificulta su asignación a un estilo histórico o a una cronología absoluta.

A modo de conclusiones se puede indicar lo siguiente:

- Responde a la tipología de iglesia rural habitual en la zona de montaña lucense. Presenta peculiaridades propias:

- Mampostería de piedra local.

- Muros gruesos y escasa altura de las naves.

- Escasos vanos y de pequeño tamaño.

- Fachada de corte pentagonal rematada en una espadaña habitual en el barroco rural gallego entre el segundo tercio del s. XVIII y mediados del s. XIX. En esta zona se realizan en lajas de pizarra motivando la ausencia de elementos decorativos.

- Pórtico o cabildo antepuesto a la fachada.

\footnotetext{
${ }^{5}$ Este trabajo fue realizado por Ángel Palomo Sánchez, del Instituto Eduardo Torroja de Ciencias de la Construcción (CSIC), en el mes de abril de 2002. Los resultados obtenidos de los análisis de estas muestras están pendientes de confirmar.
} 


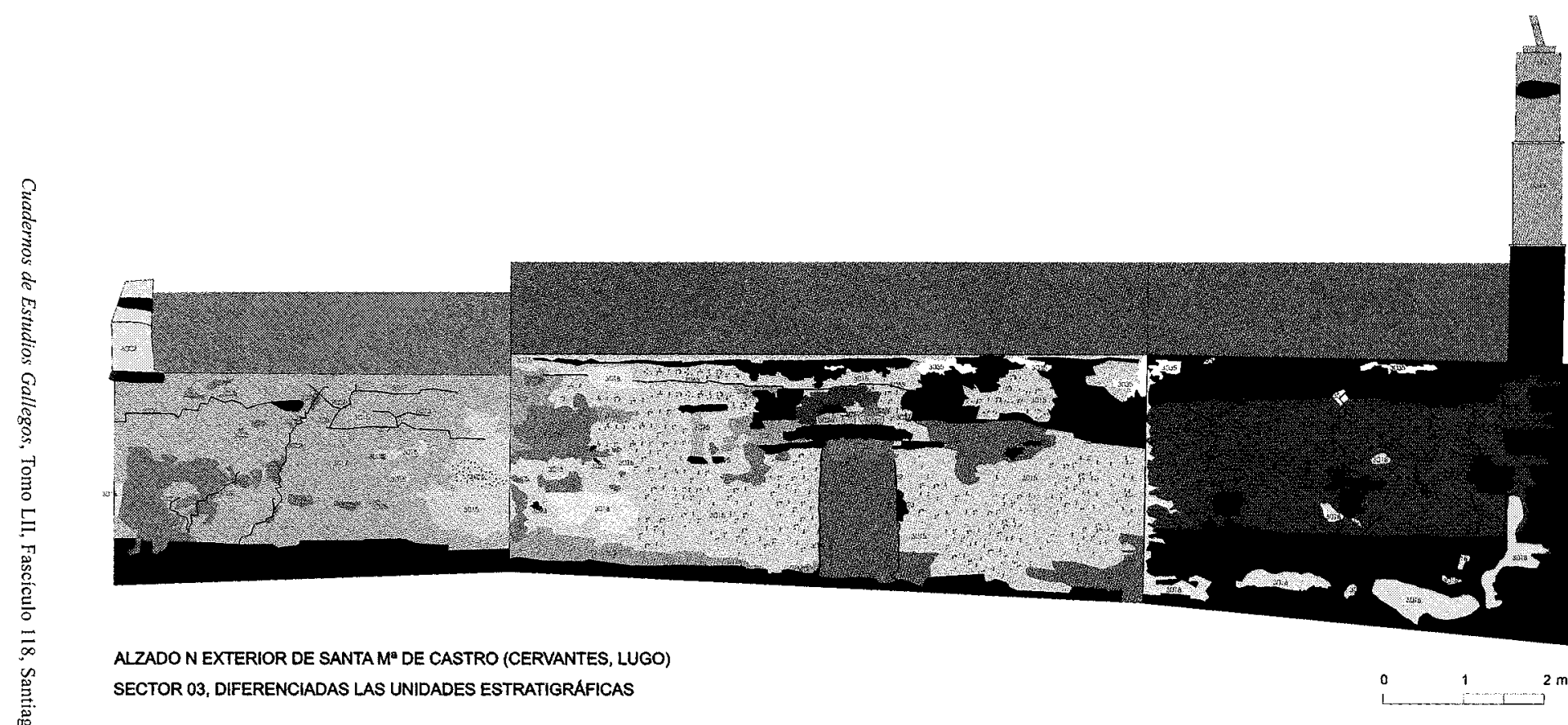

Figura 8. Alzado $\mathrm{N}$ exterior de la iglesia con la diferenciación de elementos e interfaces 
- La planta es un modelo que se repite en el arte rural gallego desde la Edad Media hasta la Edad Moderna.

- Sus elementos estructurales y aspectos técnicos, igualmente se ajustan el tipo de templo rural gallego común entre el s. XVI y el s. XIX.

\subsubsection{Resultados del análisis estratigráfico}

En primer lugar debemos indicar que la pervivencia de tipologías y técnicas constructivas en el arte rural gallego, el uso de piedra local y la ausencia de elementos de estilo, como veíamos arriba, dificultaron en gran medida la lectura e impedían determinar con claridad la secuencia histórica del edificio. Sin embargo, el rigor de esta metodología permitió llevar a cabo un análisis exhaustivo en el edificio y se cree que precisamente en estos casos, donde no se trabaja con arquitectura monumental, este tipo de análisis permiten identificar la secuencia del edificio, que de otra forma quedaría incompleta.

El primer dato que se puede extraer de la lectura es que la iglesia había sufrido numerosas reformas y remodelaciones consecutivas en el tiempo que habían afectado tanto a su estructura como a su aspecto exterior. A continuación resumimos brevemente las fases documentadas en el edificio.

\section{Fase bajomedieval: finales del s. XIII - s. XIV}

En las zonas bajas del ábside y parte del segundo tramo de la nave se identificaron restos de una fábrica con un aparejo diferente al resto de la iglesia (aunque también estaba realizada en mampostería de pizarra, los mampuestos eran de mayor tamaño y estaba asentada en hiladas bastante regulares) y a diferencia de ésta asentada a hueso. Se cree que se trataría de los restos de una planta anterior sobre la que se construye la iglesia actual, contemporánea a la necrópolis excavada y que posiblemente se adscriba a finales del s. XIII-XIV (véase apartado dedicado a la necrópolis). Se considera que este primer edificio, de menores dimensiones que el actual y que posiblemente funcionaría como capilla, tendría relación con los procesos de cristianización del castro.

Para la datación de esta fase se ha utilizado una fecha ante quem, ya que carecemos de ningún otro elemento que nos permita fechar esta actividad, pero sí se localizó un fósil director que nos permitió fechar la actividad cuya posición estratigráfica es posterior a ésta. No podemos, por el momento, avanzar ningún otro dato referente a esta fase, mientras no se lleve a cabo la excavación de la planta del templo, que nos permitiría poner en conexión el edificio y la necrópolis, así como definir la planta de esta primera construcción. 


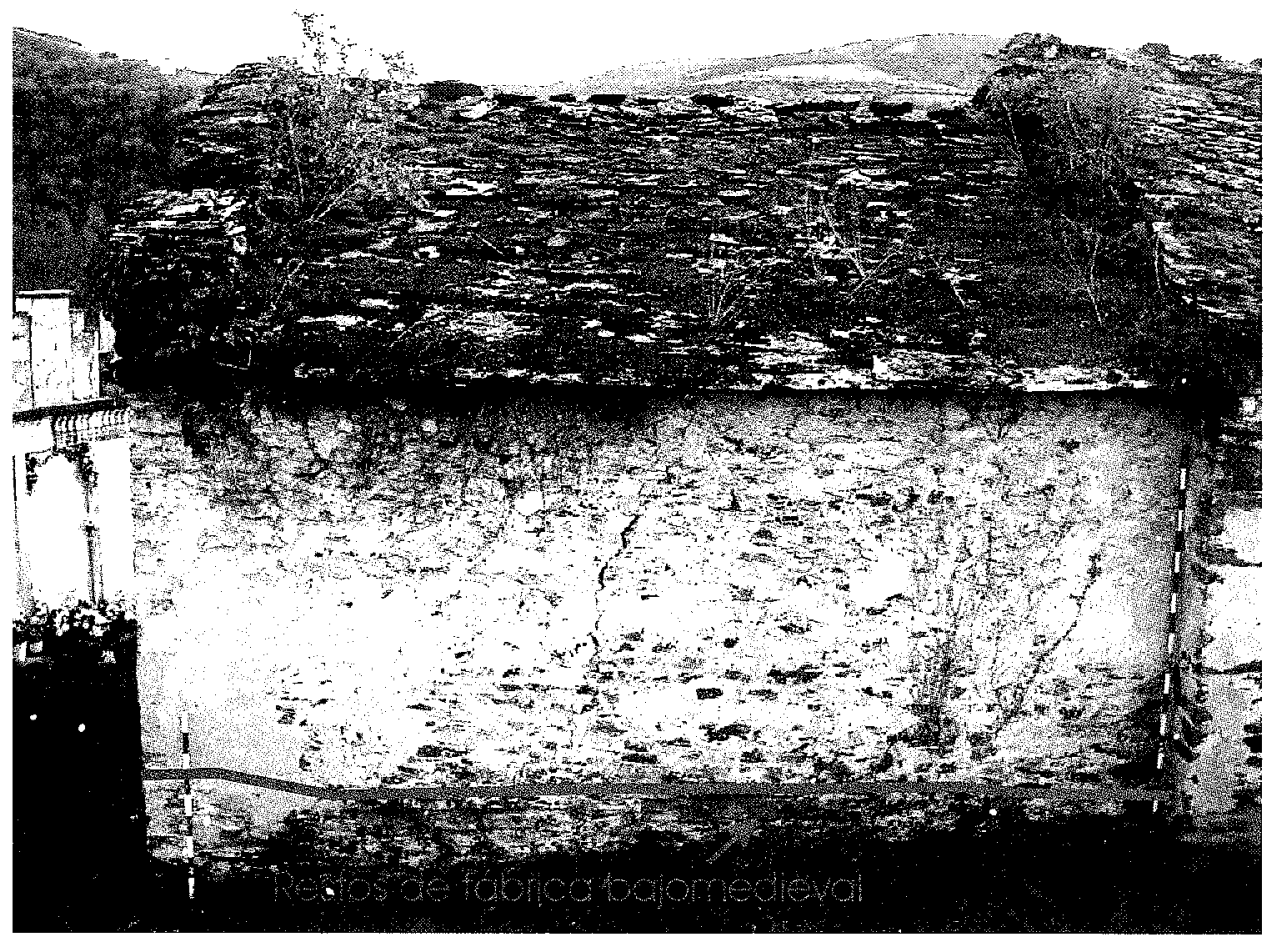

Figura 9. Alzado $\mathrm{N}$ del ábside, con la diferenciación de los restos del primer edificio.

Fase tardogótica: finales del s. XV

Sobre esta fábrica, empleada como cimentación, se levanta una nueva iglesia, posiblemente con la misma planta a finales del s. XV. De este periodo se conservan el ábside y parte de lo que constituye hoy el segundo tramo de la nave, ambas estructuras estaban realizadas en aparejo de mampostería de lajas de pizarra de pequeño tamaño, tendiendo a formar hiladas y presentaba restos de un mortero de cal, con desgrasantes de pequeño tamaño ${ }^{6}$. Conservamos como fósil director la ventana alancetada del ábside, en cuyo interior se conservan unas pinturas que como se decía hemos fechado en el s. XVI, por lo tanto esta fase se iría a un momento inmediatamente anterior a las pinturas. Por otro lado es el análisis formal de esta ventana, el que nos lleva a datar esta fase en un momento tardogótico,

\footnotetext{
${ }^{6}$ Como se decía, estamos pendientes de los resultados de las muestras de los morteros, que nos permitan contrastar los datos recogidos durante el proceso de análisis estratigráfico.
} 
en el que aún se están empleando tipos que en otras zonas ya se han sustituido por nuevas formas características ya de época renacentista.

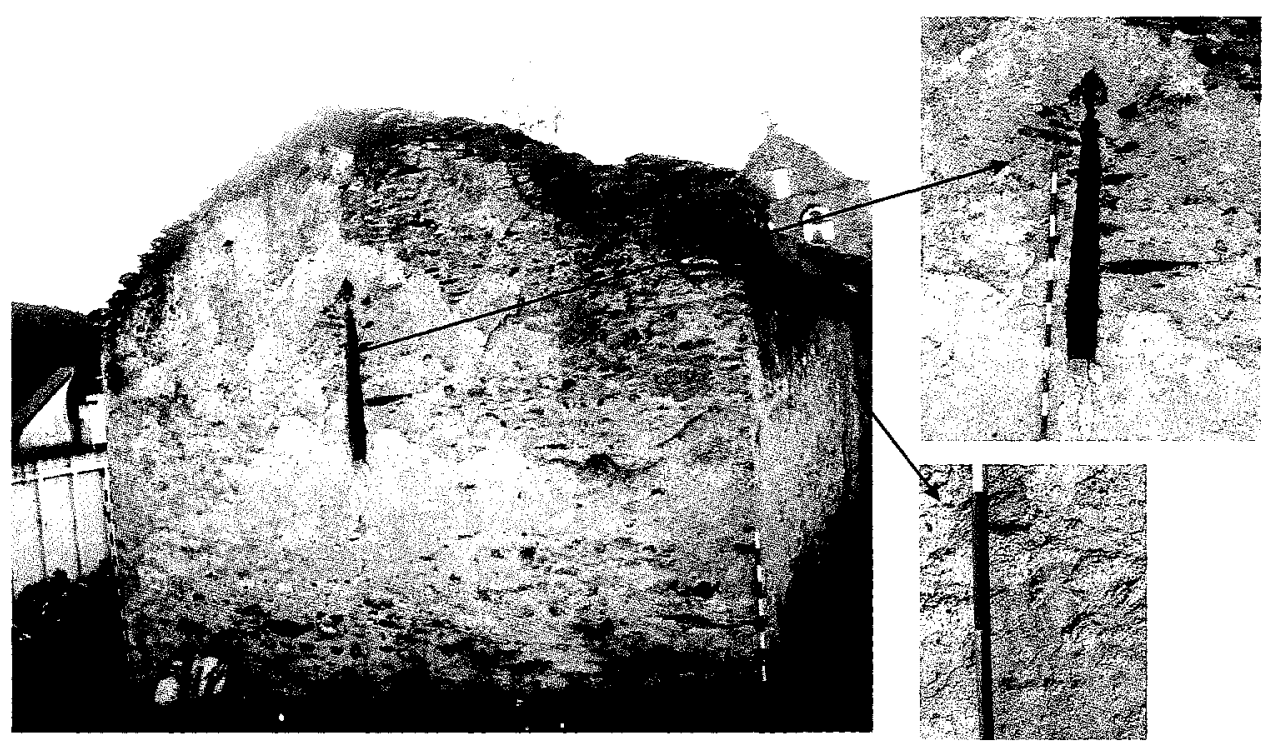

Figura 10. Alzado E del ábside con la ventana alancetada en la que se sitúan las pinturas murales; restos de estuco conservados en el alzado $\mathrm{N}$ del ábside.

\section{Fase moderna I: último tercio del s. XVI}

En el último tercio del s. XVI se produce una ampliación de la nave tardogótica hacia el W, esta ampliación posiblemente responda a la conversión del edificio en iglesia parroquial, ya que aunque existe una importante ausencia documental entre finales del s. XVI y finales del s. XVII en la documentación recogida el edificio pasa de denominarse capilla a iglesia parroquial en los documentos conservados de ambas fechas. Como consecuencia podría derivarse la necesidad de ampliar el edificio para dar cabida a un mayor número de fieles. A este periodo correspondería también la construcción de la puerta $\mathrm{N}$ del edificio, actualmente tapiada y las pinturas que cubrirían al menos el ábside, de las cuales se conservan restos visibles en el interior de la ventana alancetada del testero, aunque se cree que podrían conservarse también en el ábside, actualmente encalado, a no ser que hayan sido afectadas por un incendio que hemos documentado en el s. XX por fuentes orales y que motiva la reforma del mismo.

Por otro lado, se ha documentado la existencia de restos de estucado en el exterior del ábside (ver figura 10) y en diferentes partes del segundo tramo de la nave, 
de los cuales se han recogido muestras para su análisis. Se han fechado estos restos en esta misma fase, ya que se considera que corresponderían a la misma función que las pinturas del ábside, un embellecimiento interior y exterior del edificio relacionado con la nueva entidad del edificio como iglesia parroquial.

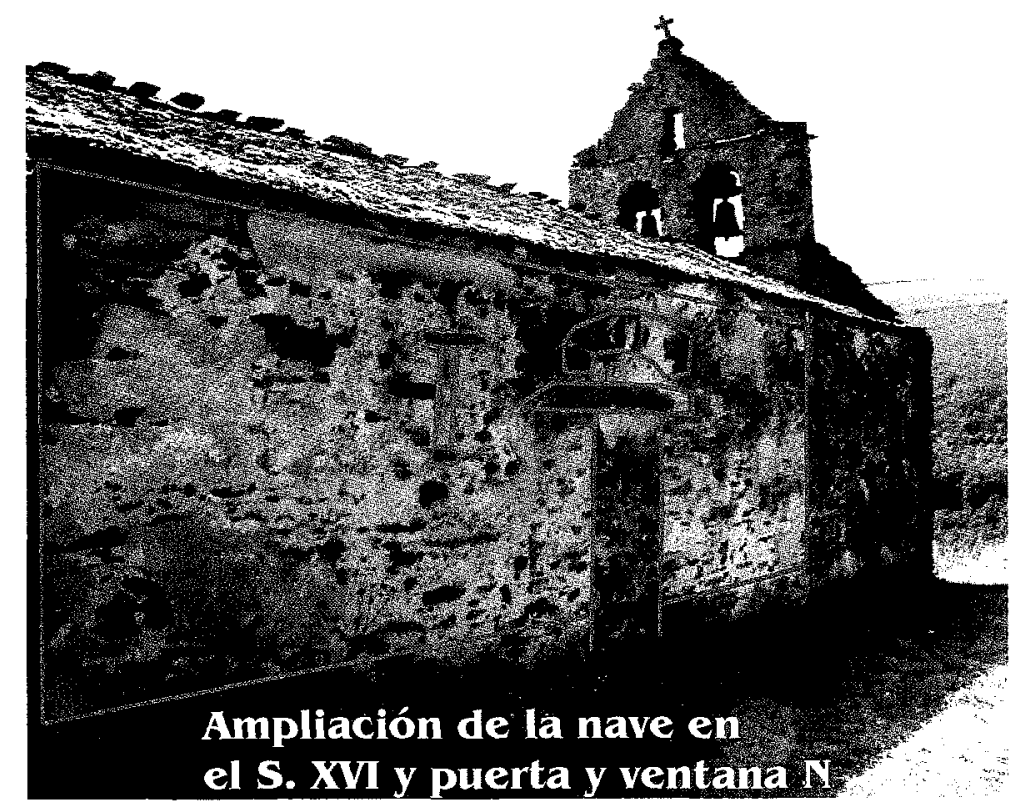

Figura 11. Alzado $\mathrm{N}$ de la nave, diferenciación de la ampliación de la nave en el S. XVI y vanos de este periodo cegados en la actualidad.

\section{Fase moderna II: mediados / finales del S. XVII}

Ya en época barroca se produce una nueva ampliación de la nave de la iglesia hacia el W, que coincide con un aumento poblacional en la zona. Se ha identificado en esta fase un cambio de aparejo con respecto a las anteriores, aunque se trata también de un aparejo de mampostería de pizarra, ahora se emplean bloques de mayor tamaño y el aparejo es irregular, sobre todo en las zonas más altas del edificio. En el alzado $\mathrm{N}$ se han determinado dos subetapas que vienen delimitadas por una hilada de lajas de pizarra en la zona baja. Posiblemente por las características del terreno, ya se ha indicado que el edificio está situado sobre un espolón concretamente sobre la croa $^{7}$ del castro, esta ampliación es de menores dimensiones en

\footnotetext{
${ }^{7}$ Acrópolis.
} 
anchura que el segundo tramo de la nave (el más oriental), empleando en los alzados $\mathrm{N}$ y $\mathrm{S}$ distintas soluciones, concretamente en el $\mathrm{N}$ se resuelve mediante un retranqueo mientras que en el $\mathrm{S}$ se produce un ligero giro de la planta hacia el $\mathrm{N}$ (ver figura 5). Se desconoce cómo sería el cierre de esta ampliación por el W, ya que la fachada que presenta en la actualidad la construcción correspondería a la fase siguiente, cabe la posibilidad de que se realizara un cierre provisional o que se mantuviera el cierre de la fase anterior.
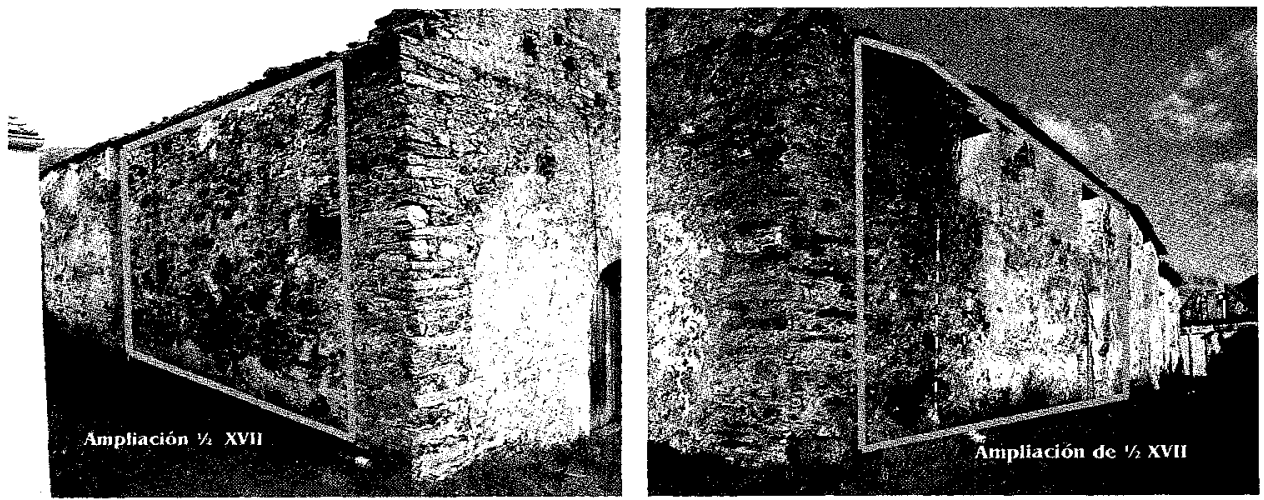

Figura 12. Alzados N y S de la nave con la diferenciación de la ampliación de mediados del siglo XVII.

\section{Fase moderna III: finales del S. XVIII - principios del s. XIX}

En este momento se lleva a cabo el cierre del edificio por el $\mathrm{W}$ mediante una fachada de corte pentagonal rematada en una espadaña de dos cuerpos a la que se accedería mediante una escalera lateral por el lado $S$, a la que se adosa un pórtico o cabildo. En la actualidad se ha perdido el cabildo, pero se conservan en otras iglesias de la zona (ver figuras 13 y 14). Estas estructuras funcionaban como pórticos para resguardo de los feligreses, pero también, y de ahí su denominación, como lugares donde el cabildo llevaba a cabo tareas administrativas en relación con la parroquia. También se ha perdido la escalera de acceso a la espadaña.

Ambas pérdidas se producen cuando a principios-mediados del s. XX el párroco lleva a cabo obras en el entorno de la iglesia para crear un acceso directo desde el W mediante una escalera, lo cual obliga a eliminar la estructura que forma el cabildo y a su vez las escaleras ya que se apoyaban en éste. Ambos elementos se conservan hoy en día en la memoria de los vecinos de Cervantes, como se ha recogido en fuentes orales. 

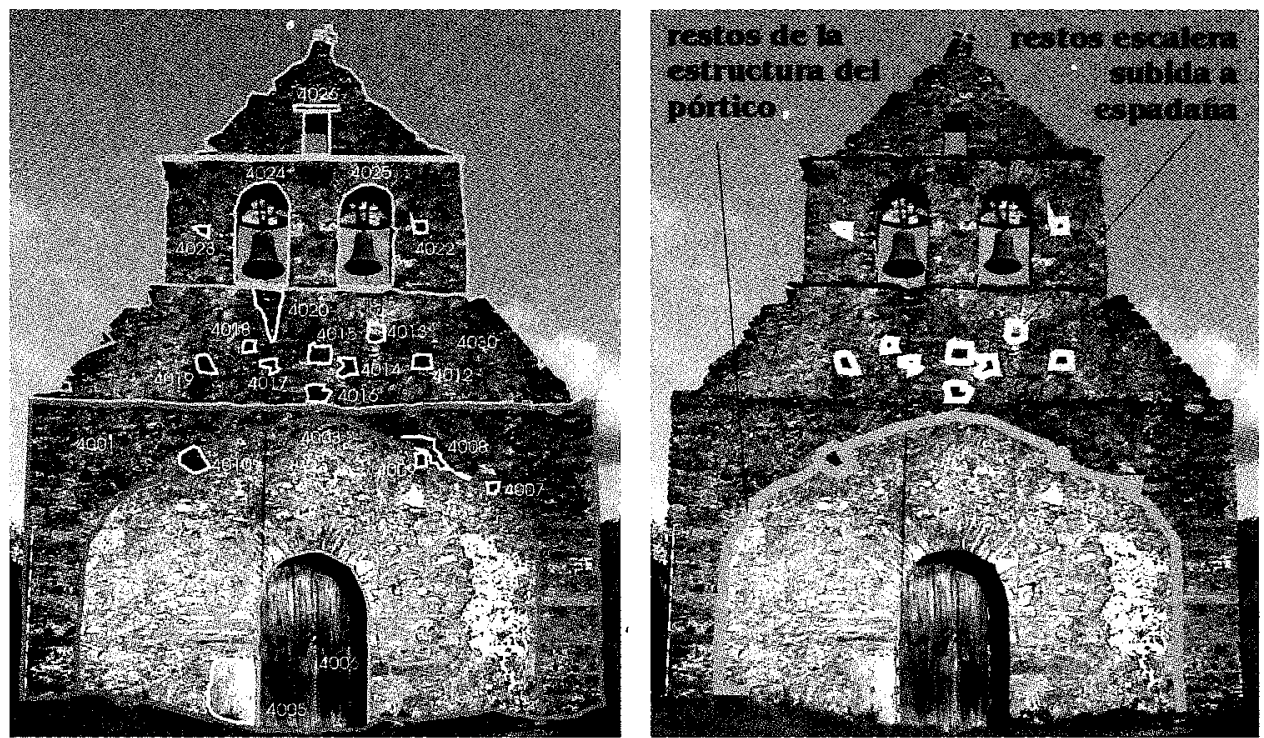

Figura 13. Fachada W de Santa María. En la fotografia de la izquierda se recogen las unidades estratigráficas diferenciadas y numeradas; en la fotografía de la derecha, las unidades diferenciadas correspondientes al pórtico y escalera de subida al campanario desaparecidos.
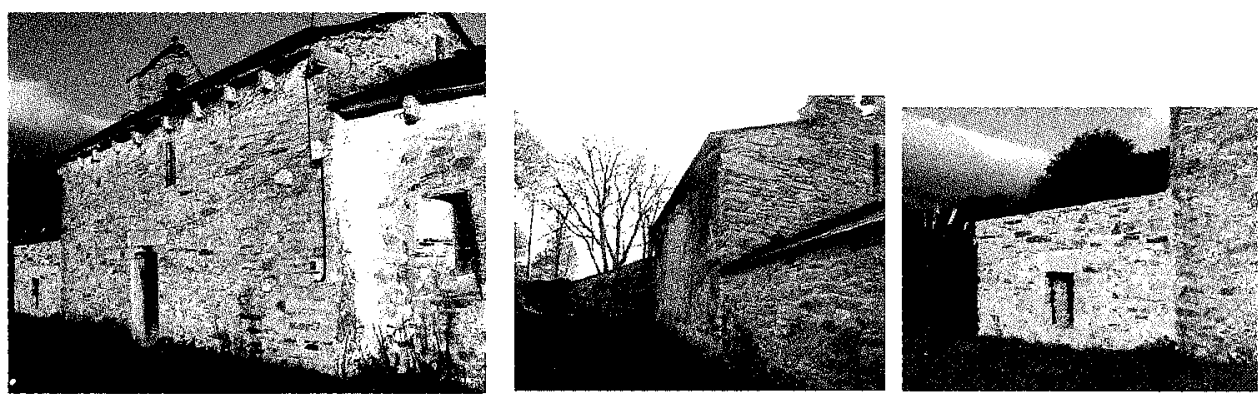

Figura 14. Iglesia parroquial de San Cosme de Ouselles (Vilar de Frades, Becerreá, Lugo). Vista de la iglesia desde el SE en la fotografía de la izquierda, alzado S del pórtico o cabildo adosado a su fachada W en la fotografía de la derecha y fotografía del alzado $\mathrm{N}$ del cabildo en la central.

Asimismo corresponderían a esta fase la apertura de ventanas rectangulares con doble derrame en el alzado $\mathrm{S}$, la apertura de la puerta $\mathrm{S}$, de las mismas características que la $\mathrm{W}$, ambas con jambas rectas al exterior y rematadas en un arco de medio punto dovelado realizado en lajas de pizarra y al interior con jambas con derrame, la $\mathrm{S}$ rematada en un dintel de madera y la $\mathrm{W}$ en un arco escarzano. También se cierran los vanos del alzado N. Finalmente, se lleva a cabo el revestimiento exterior de todo el edificio. 


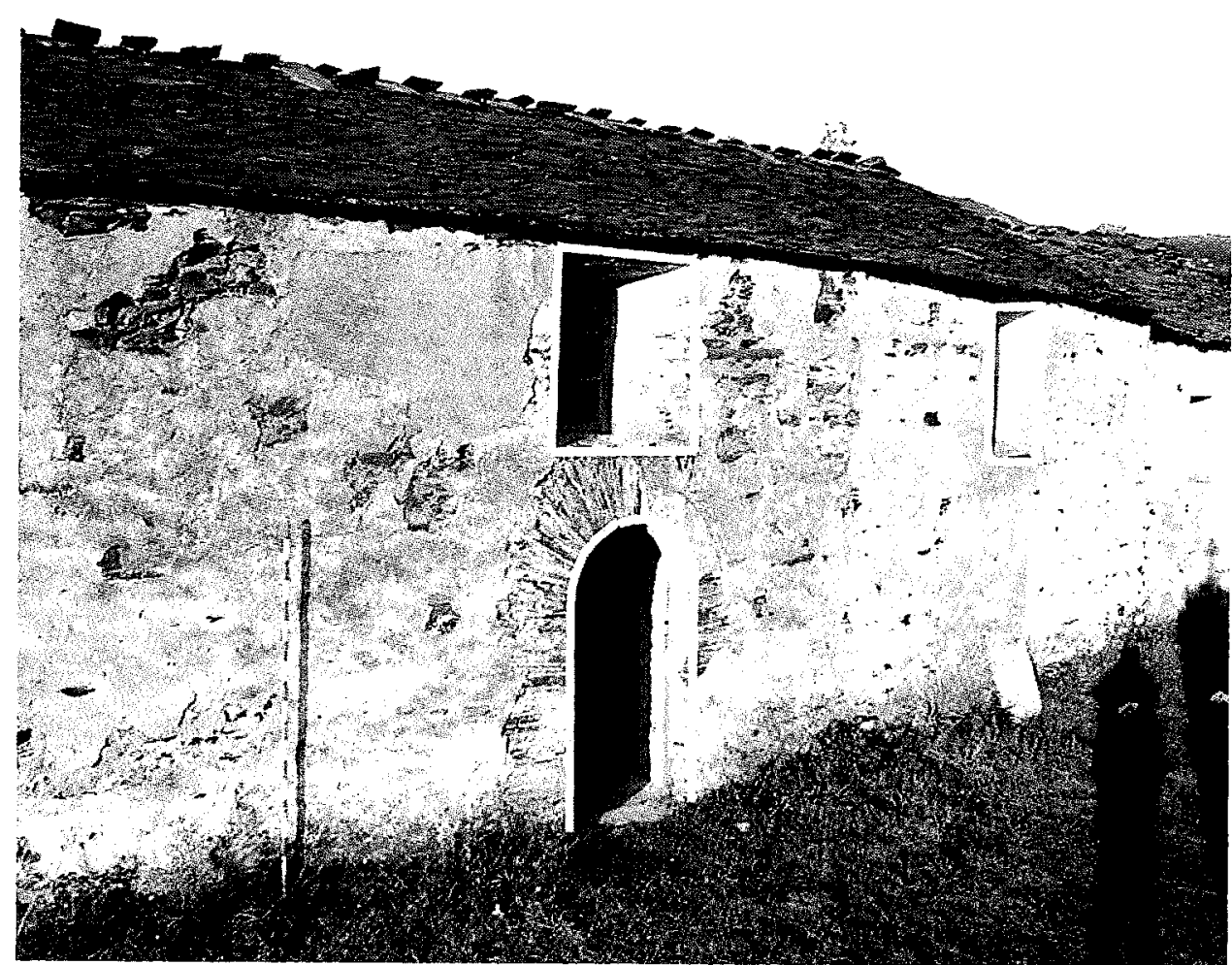

Figura 15. Detalle del alzado $\mathrm{S}$ del edificio, viéndose el tipo de ventanas y la puerta $\mathrm{S}$, abiertas en la Fase Moderna III a finales del S. XVIII, principios del S. XIX.

\section{Fase contemporánea I: $\mathbf{s . ~ X I X ~}$}

En esta fase las obras llevadas a cabo no afectan a la estructura del edificio, podrían denominarse obras menores. A lo largo del S. XIX se producen roturas importantes en los muros, motivadas en parte por las reformas llevadas a cabo en la fase anterior. Éstas afectan fundamentalmente al alzado $\mathrm{S}$ del edificio, debajo de las ventanas, y al ábside. En este momento se llevan a cabo las reparaciones de estas roturas, así como un nuevo revestimiento del exterior de la construcción.

\section{Fase contemporánea II: s. XX}

Ya en el S. XX se cubre nuevamente el edificio, con una cubierta a dos aguas realizada en lajas de pizarra, como se ha documentado gracias a los libros de fábrica conservados de este siglo. También se llevan a cabo reformas en el interior del templo, como es la reforma del artesonado que se soluciona ahora con un entabla- 


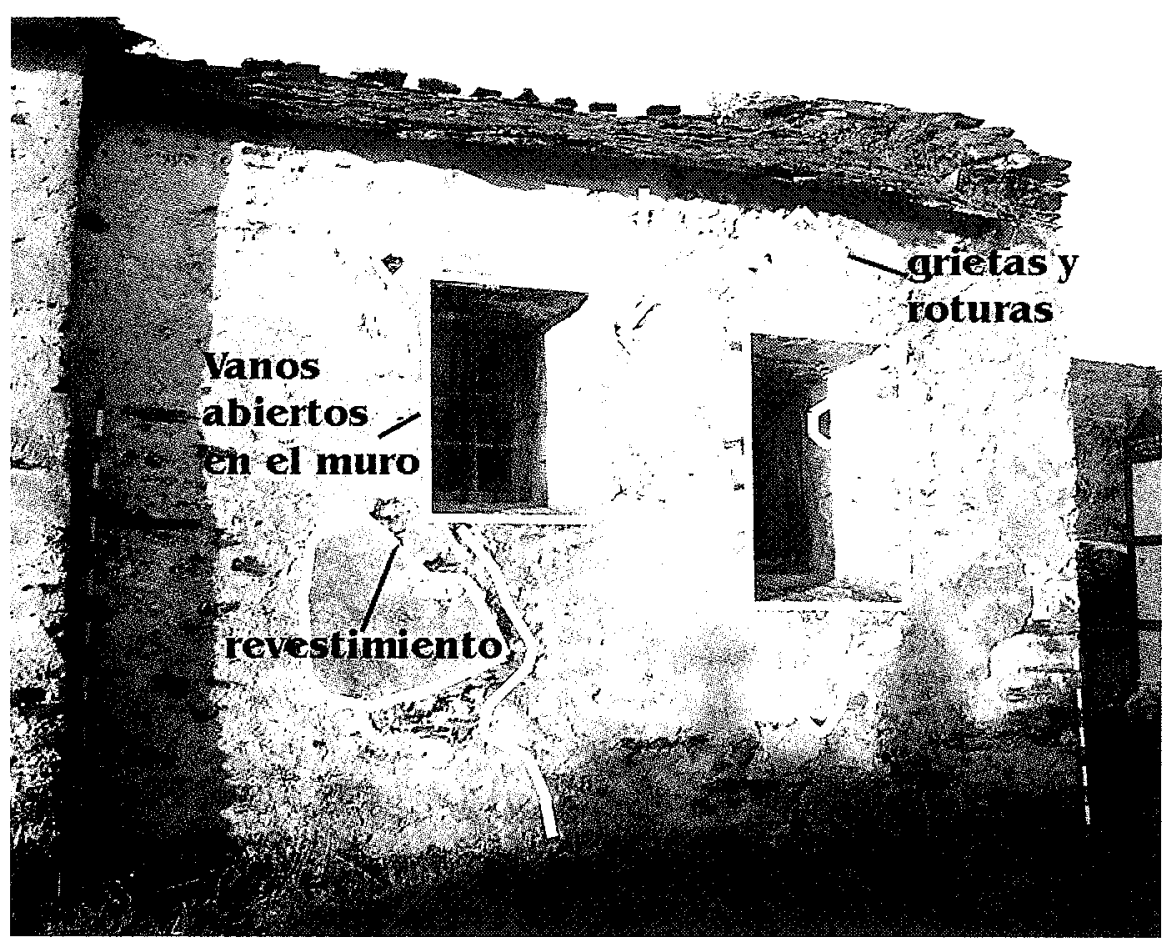

Figura 16. Alzado S del ábside. En la fotografía se diferencian las ventanas abiertas en la fase anterior y las roturas y reparaciones provocadas por éstas, llevadas a cabo en esta fase.

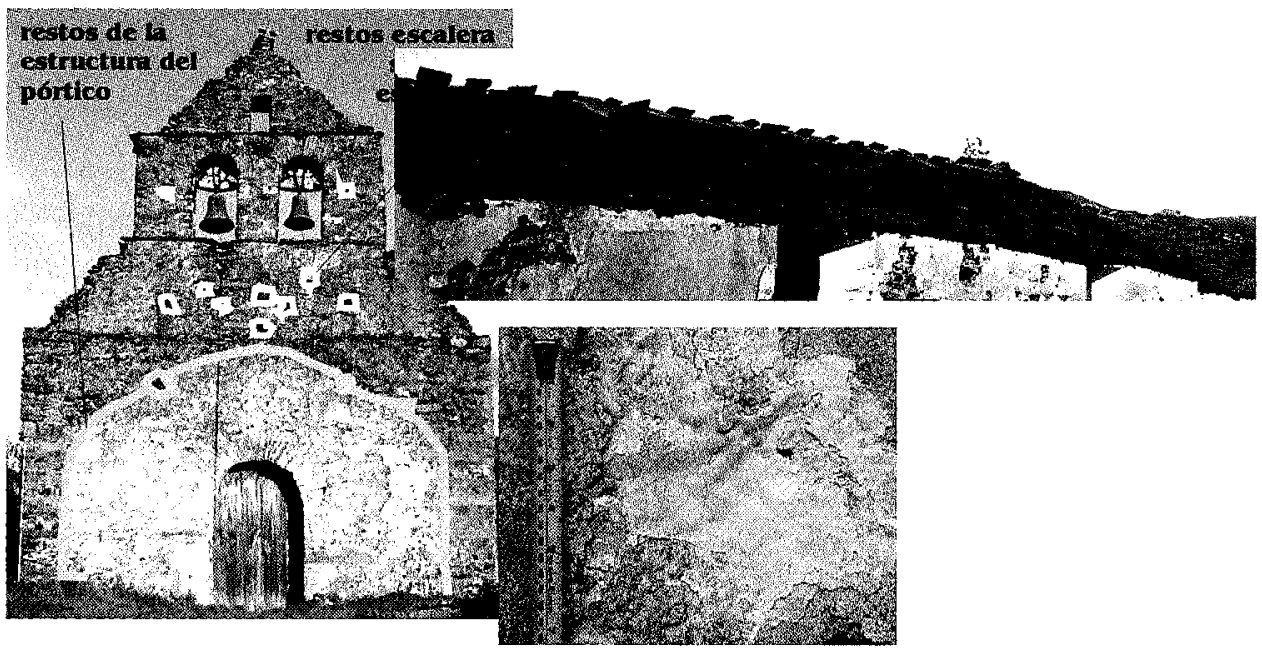

Figura 17. Elementos pertenecientes a la fase del S. XX: pórtico y escalera eliminadas en la fachada $\mathrm{W}$, nueva cubierta de pizarra y revestimiento y restos de pintura en el exterior del edificio. 
do de láminas de madera, se reforma el ábside mediante una solución que se cree poco acertada (se emplea en suelo y altar plaquetas de loza) y se reviste todo el interior y se pinta de blanco. Asimismo se elimina, como se decía, el cabildo y la escalera de acceso a la espadaña. Finalmente se llevan a cabo nuevos revestimientos puntuales en el exterior de la construcción.

\subsection{Finalidad del análisis}

Como se veía al principio, el análisis efectuado en esta pequeña iglesia parroquial tenía una finalidad muy concreta, que a su vez conllevaba otras intenciones. Por una lado, se pretendía impulsar una línea de investigación que se viene desarrollando en los últimos años primero en el Laboratorio de Arqueología y Formas Culturales (IIT, USC) y actualmente en el Laboratorio de Arqueología del Instituto de Estudios Gallegos Padre Sarmiento (CSIC-Xunta de Galicia), fundamentada en la Arqueología de la Arquitectura como marco teórico-metodológico, y que en la actualidad, en Galicia, está todavía en sus fases iniciales. Por otro lado, y en este mismo sentido, se cree que es necesario establecer pautas y criterios de actuación en Arqueología de la Arquitectura y, concretamente en el caso desarrollado en este texto, en una de las metodologías desarrollas en el seno de esta disciplina como es el análisis estratigráfico de paramentos que, como se decía, en nuestra comunidad está todavía iniciándose.

Además, ante la posibilidad, dado el estado de ruina en que se encuentra el edificio, de que se efectúe un proyecto de restauración del mismo, se cree que podía contribuirse al mismo con los resultados obtenidos del análisis. En relación con este punto, deberían tenerse en cuenta los siguientes aspectos:

- La información generada durante la presente investigación.

- La necesidad de efectuar una nueva lectura una vez levantados los revestimientos, sobre todo en el interior del edificio donde no se pudo efectuar un análisis completo debido a que no se observaban sus fábricas, ya que se cree que podrían conservarse pinturas al menos en el ábside, en relación con las pinturas documentadas en el abocinamiento de la ventana absidial.

- La necesidad de realizar una excavación en área en el interior del edificio y parte de su exterior, que permita conectar estratigráficamente castro, necrópolis cristiana y primitiva capilla.

Finalmente, se pretendía contribuir al interés demostrado por la empresa arriba mencionada por que se efectuase un estudio completo del edificio que permitiese establecer una conexión entre la iglesia y el yacimiento excavado, en caso de exis- 


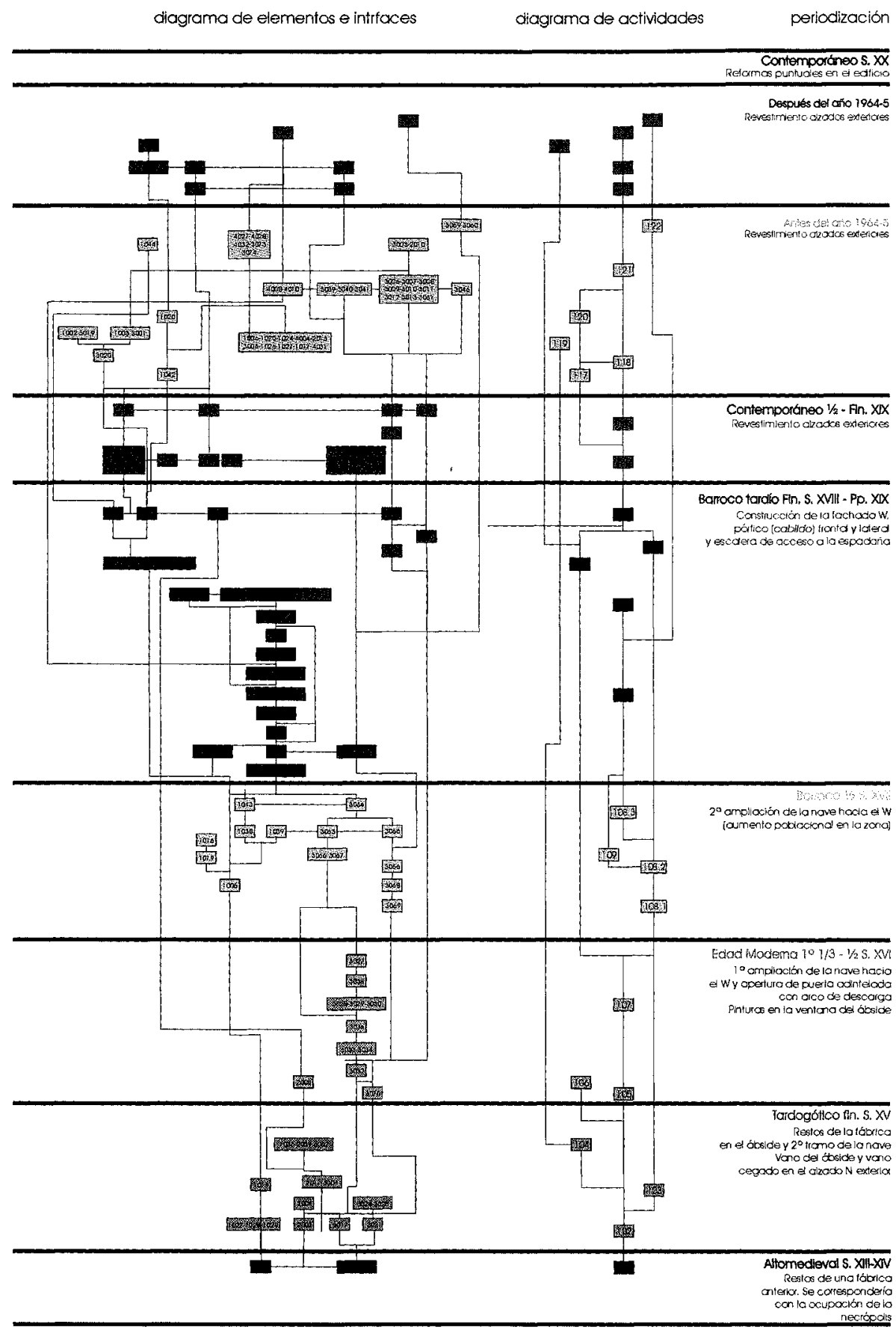

Figura 18. Diagrama estratigráfico de Elementos y Actividades y su periodización.

Cuadernos de Estudios Gallegos, Tomo LII, Fascículo 118, Santiago 2005. (Págs. 9 - 38) 
tir. Su intención era la de conseguir que el estudio fuera contemplado en el proyecto de restauración y continuar con los trabajos en el castro, que deberían implicar su revalorización, dada la potencialidad del yacimiento.

\section{CONCLUSIONES}

Llegados a este punto, se cree que el trabajo desarrollado en esta pequeña iglesia parroquial ha contribuido por un lado al mejor conocimiento del edificio ( $y$, por extensión, de la arquitectura eclesiástica de ámbito gallego) y por otro, y con ello se cubre uno de los objetivos fundamentales del trabajo, al desarrollo de la $\mathrm{Ar}$ queología de la Arquitectura en Galicia, que sólo a través de su puesta en práctica permitirá establecer pautas teórico-metodológicas en el futuro.

Como se ha visto, a falta de realizar una excavación arqueológica en el entorno e interior del edificio, con gran seguridad existe una conexión entre la necrópolis bajomedieval exhumada durante las excavaciones arqueológicas y el primer edificio, posiblemente una pequeña capilla, levantado en Santa María de Castro.

Por otro lado, lejos de tratarse de una construcción contemporánea o de los últimos años de la Edad Moderna, como se apuntaba en la bibliografía arriba menciona$\mathrm{da}$, estamos ante un edificio que inicia su andadura en época bajomedieval y que desde entonces ha ido modificándose atendiendo a varios factores, de orden social, religioso o meramente estilístico. Así, se podría hablar de al menos cinco construcciones superpuestas y consecutivas en el tiempo, que han modificado la estructura inicial del tiempo y en cierto modo la han enmascarado. En este sentido, si se abordan las construcciones históricas desde planteamientos meramente estilísticos puede caerse nuevamente en el error de fechar las construcciones por su aspecto exterior o por sus elementos estilísticos que, en casos como éste, muchas veces están ausentes y pueden conducir a errores. Sin embargo, la Arqueología de la Arquitectura proporciona metodologías de análisis que a través de la deconstrucción profundizan en todos los aspectos del edificio: su emplazamiento, estratigrafía, técnica constructiva, elementos formales,... Ello nos permite datar primero de forma relativa y, posteriormente, acudiendo a otras disciplinas, de forma fiable la fábrica.

Evidentemente, y a pesar de la flexibilidad de esta metodología, si no se lleva a cabo de forma rigurosa y científica se podría incurrir en graves errores que nos llevarían a un análisis inadecuado y a una datación poco fiable. 


\section{BIBLIOGRAFÍA}

BALSA DE LA VEGA, R. 1912. Catálogo-Inventario monumental y artístico de la Provincia de Lugo: lo llevó a término por Real Orden de 21 de junio de 1911.

CABALLERO ZOREDA, L. 1995. Método para el análisis estratigráfico de construcciones históricas o «lectura de paramentos». Informes de la Construcción, 453: 37-46. Madrid: CSIC.

FERNÁNDEZ GÓMEZ, R.Ma 1998. El Arte Religioso en la Sierra Oriental de la provincia de Lugo, por tierras del Camino Primitivo (s. XV-XX). Catalogación. Tesis doctoral (editada en $\mathrm{CD})$.

GARCÍA CONDE, A. y LÓPEZ VALCÁRCEL, A. 1999. Episcológico Lucense. Lugo: Fundación Caixa Galicia.

GARCÍA IGLESIAS, J.M. 1979. La pintura en Galicia durante la Edad Moderna: el siglo XVI. Santiago: Universidad de Santiago de Compostela, Facultad de Geografia e Historia.

GARCÍA IGLESIAS, J.M. 1986. La pintura manięrista en Galicia. A Coruña: Fundación Barrié de la Maza.

GARCÍA IGLESIAS, J.M. 1989a. Pinturas inéditas en Galicia del s. XVI. Cuadernos de Estudios Gallegos, XXXVIII, $\mathrm{n}^{\circ} 103$.

GARCÍA IGLESIAS, J.M. 1989b. Pinturas murais de Galicia. Santiago de Compostela: Subdirección Xeral do Patrimonio Histórico (Servicio de Arquitectura).

LÓPEZ GONZÁLEZ, L.F. y ÁLVAREZ GONZÁLEZ, Y. 2000. El poblado minero de Sta. María de Castro (Cervantes, Lugo). III Congresso de Arqueologia Peninsular, Volume V, «Proto-História da Península Ibérica» (Porto, ADECAP, 2000).

LÓPEZ GONZÁLEZ, L.F., ÁLVAREZ GONZÁLEZ, Y. y LÓPEZ MARCOS, M.A. 1996. Informe preliminar da segunda campaña de escavación, consolidación e acondicionamento do Castro de Santa María de Castro (Cervantes, Lugo). (Informe inédito depositado en la Dirección Xeral de Patrimonio Cultural en 1996).

LÓPEZ GONZÁLEZ, L.F., ÁLVAREZ GONZÁLEZ, Y. y LÓPEZ MARCOS, M.A. 1999. Informe valorativo da actuación arqueolóxica no Castro de Santa María (Cervantes, Lugo). (Informe inédito depositado en la Dirección Xeral de Patrimonio Cultural en 1999).

LÓPEZ VALCÁRCEL, A. 1996. Guía de la Diócesis de Lugo. Suplemento del Boletín Oficial del Obispado de Lugo. Lugo: Obispado.

LÓPEZ VALCÁRCEL, A. 1991. Las visitas pastorales del Obispo D. Lucas Bustos a la Diócesis de Lugo, Memoria Eclesiae, XV. En Hevia Ballina, A. (Ed.). 1997. Las visitas pastorales en el ministerio del obispo y archivos de Galicia: santoral hispano-mozárabe en las diócesis de España. Madrid: Asociación de Archiveros de la Iglesia en España. Actas del XIII Congreso de la Asociación de Archiveros de la Iglesia en España (Sevilla 11 al 16 de septiembre de 1997).

VALIÑA SAMPEDRO, E. 1975-1983. Inventario artístico de Lugo y su provincia. (V. II. 1975). Madrid: Ministerio de Educación y Ciencia.

VALIÑA SAMPEDRO, E. 1991. Catálogo de los Archivos parroquiales de la Diócesis de Lugo. Lugo: Diputación Provincial, Servicio de Publicaciones. 
VÁZQUEZ, R.Ma . 2000. La actividad artistica en el Camino Francés de las peregrinaciones en la provincia de Lugo entre 1500-1800. Tesis doctoral (edición en CD).

VILA JATO, MD. y GARCÍA IGLESIAS, J.M. 1993. Galicia en la época del Renacimiento. En Rodríguez Iglesias, F. (Dir.) 1993. Galicia Arte. XII. A Coruña: Hércules.

VV.AA. 1915. Guía Eclesiástica de la Diócesis de Lugo. Lugo: Gerardo Centro.

VV.AA. 1941-1978. Boletín de la Comisión Provincial de Monumentos Históricos y Artísticos de Lugo. Tomos: I, II, V (3 vol.), VI (1954-5), VI (1956-7), VII (1963), VII (1964), VIII (1969-70), IX (1974-5). Lugo: Comisión de Monumentos Históricos y Artísticos. 